\section{Back Pain Due to Lumbar Gouty Flare - A Prospective Diagnosis}

To the Editor:

We read with interest the article by Konatalapalli, et $a l^{1}$. The authors described a computed tomographic (CT) study to assess the prevalence of spinal tophi or characteristic erosions (which also result from tophi ${ }^{2}$ ) in patients with gout. The prevalence was rather high (around 35\%), even higher than the rate previously reported by these authors in The Journal ${ }^{3}$. As discussed, several factors may have influenced these results; the spine might be prone to monosodium urate (MSU) crystal deposition, because the spine is a common location for osteoarthritis ${ }^{4}$, and a predilection for osteoarthritic joints has been shown in gout ${ }^{5}$.

Clinical presentations of gout essentially relate to joint inflammation or either palpable tophi or problems related to them in different locations ${ }^{6}$. Our knowledge about gouty spinal inflammation remains anecdotal. We recently had a case of axial involvement by gout.

An 85-year-old man with a long history of crystal-proven tophaceous gout, irregularly followed and treated, came to our clinic walking with a forward bent and complaining of intense and persistent low back pain for 2 months. Pain was also nocturnal, and he had to sleep in an armchair. $\mathrm{He}$ mentioned that he had been unable to walk upright in the same period. No neurological impairment was detected. In light of his extensive gout, lumbar involvement was suspected, and oral prednisone $30 \mathrm{mg} /$ day was prescribed. After $48 \mathrm{~h}$ he entered the clinic walking upright and claimed that the pain had improved so promptly that he could sleep again in his bed. To further determine the origin of the pain, lumbar magnetic resonance imaging (MRI) was ordered. This showed nodules consistent with tophi at the L4-L5 interapophyseal joints, with low signal intensity in T1 sequences and high signal intensity in $\mathrm{T} 2$ sequences, and homogeneous enhancement after gadolinium administration (Figure 1), all in keeping with acute, intense lumbar inflammation. Lumbar spinal stenosis was found at the same level. CT showed characteristic punched-out erosions with overhanging margins in vertebral pedicles (Figure 2) and nodules consistent with tophi.

The diagnosis of a flare of spinal gout had been suspected, and a very short course of prednisone was enough to treat a 2-month flare. The need for forward bending may relate to the occurrence of the flare at a level with
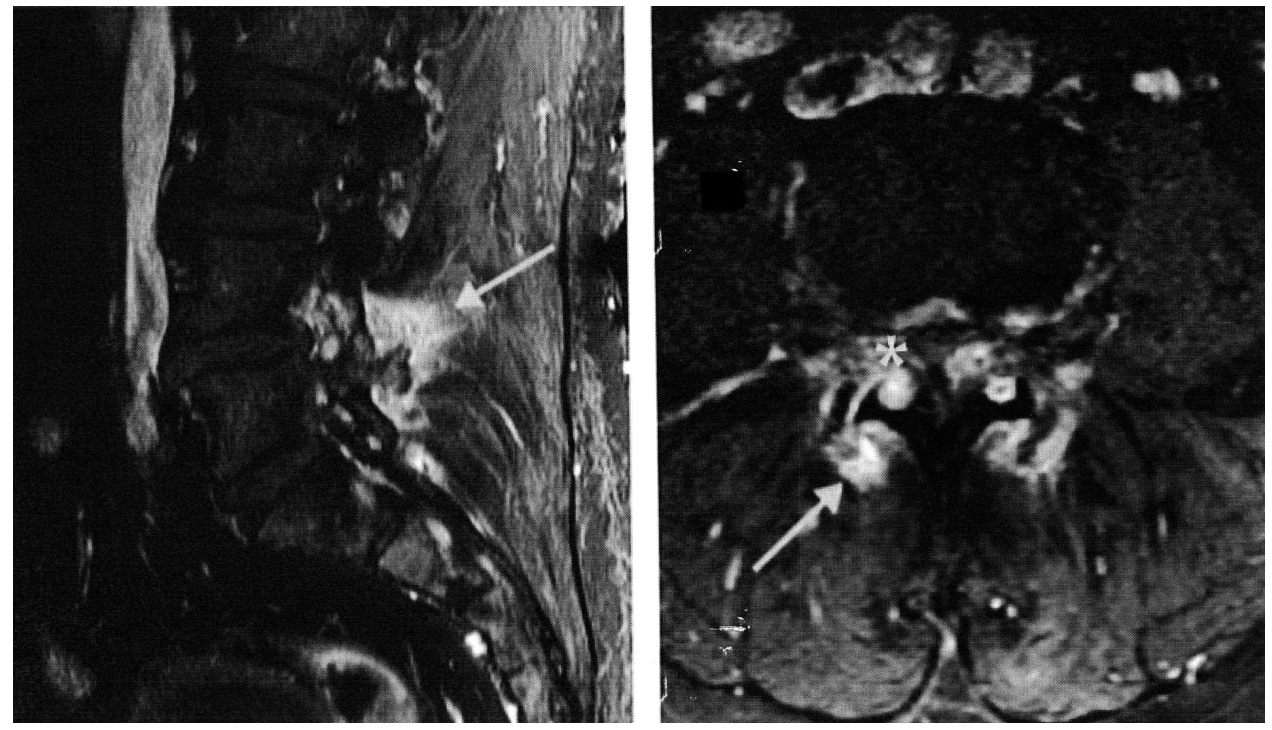

Figure 1. MRI of the lumbar spine, L4-L5 level. Sagittal (left) and axial (right) T1 fat-saturated images after gadolinium administration show contrast enhancement around interapophyseal joints (arrows) and nodules compatible with tophi (star).
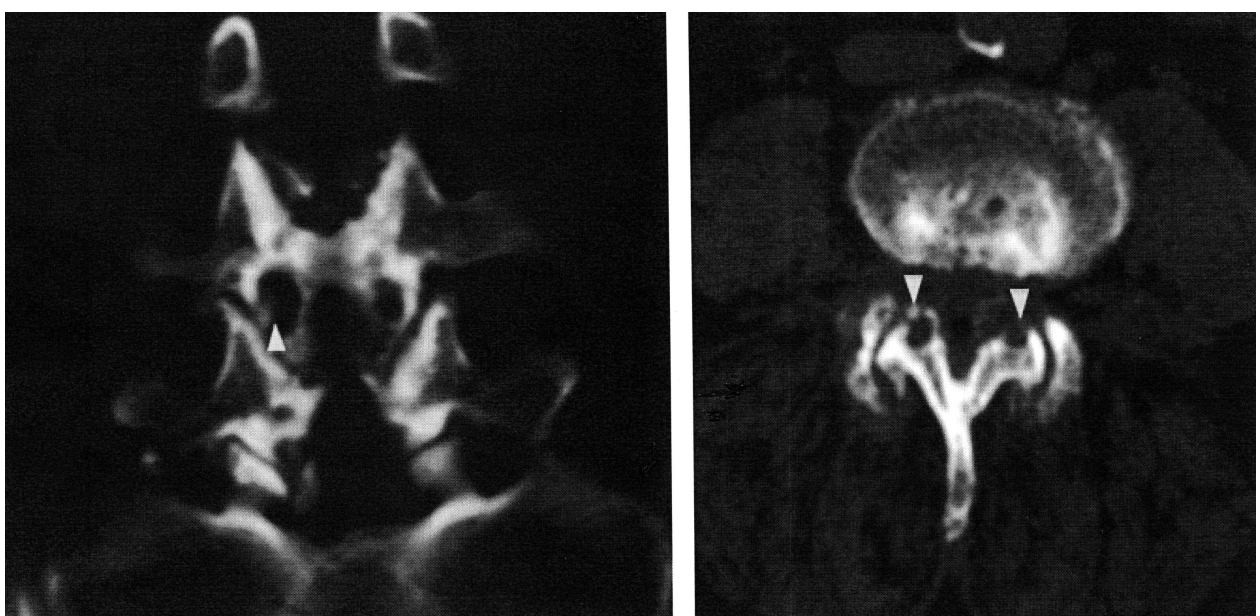

Figure 2. CT scan of lumbar spine, L4-L5 level. Coronal (left) and axial (right) images show characteristic punched-out erosions on the interapophyseal joints (arrowheads). 
spinal stenosis that became narrower and symptomatic because of the flare-related edema. A definitive diagnosis would require identification of MSU crystals at the site of inflammation, but the longterm and extensive gout of our patient, the rapid response to treatment, and the characteristic erosions shown by CT made other possibilities very unlikely. In the absence of clinical data, MRI appears to us less useful to suggest gout although it shows inflammation-related edema well - while CT scanning may show highly specific lesions. If available, dual-energy CT may provide a more direct proof of the presence of MSU deposits at this site.

Konatalapalli, et al ${ }^{1,3}$ showed that MSU crystal deposits in the form of tophi are common in the lumbar spine in patients with advanced gout. In those reports, the only clinical data provided are the lack of relation of lumbar tophi with pain ${ }^{1}$. An extensive literature review shows that spinal gout is most often reported because of mechanical consequences of tophi such as root or cord compression, and the disease tends to remain unsuspected until surgery is performed. Lumbar pain and fever with a suspicion of an abscess is another possibility that can be clarified by a biopsy or percutaneous aspiration.

Konatalapalli, et $a l^{1,3}$ and our case highlight that gout should be kept in the differential diagnosis of back complaints, especially in patients known to have gout. A clear response to a short course of oral corticosteroids might be a useful lead when spinal crystal arthritis is suspected.

MARIANO ANDRÉS, MD, Sección de Reumatología, Hospital General Universitario de Alicante; PALOMA VELA, MD, PhD, Sección de Reumatología, Hospital General Universitario de Alicante, and Departamento de Medicina Clínica, Universidad Miguel Hernández de Elche; LUCIAN CRISTIAN VOLAR, MD, Unidad de Resonancia Magnética, Inscanner UTE; YANNE AVILÉS, MD, Servicio de
Radiología, Hospital General Universitario de Alicante; ELISEO PASCUAL, MD, PhD, Sección de Reumatología, Hospital General Universitario de Alicante, and Departamento de Medicina Clínica, Universidad Miguel Hernández de Elche. Address correspondence to Dr. M. Andrés, Hospital General Universitario de Alicante, Seccion de Reumatologia, Pintor Baeza 12, Alicante 03010, Spain.

E-mail: drmarianoandres@gmail.com.

\section{REFERENCES}

1. Konatalapalli RM, Lumezanu E, Jelinek JS, Murphey MD, Wang H, Weinstein A. Correlates of axial gout: A cross-sectional study. J Rheumatol 2012;39:1445-9.

2. Dalbeth N, Clark B, Gregory K, Gamble G, Sheehan T, Doyle A, et al. Mechanisms of bone erosion in gout: A quantitative analysis using plain radiography and computed tomography. Ann Rheum Dis 2009;68:1290-5.

3. Konatalapalli RM, Demarco PJ, Jelinek JS, Murphey M, Gibson $\mathrm{M}$, Jennings B, et al. Gout in the axial skeleton. J Rheumatol 2009;36:609-13.

4. Kalichman L, Li L, Kim DH, Guermazi A, Berkin V, O’Donnell CJ, et al. Facet joint osteoarthritis and low back pain in the community-based population. Spine 2008;33:2560-5.

5. Roddy E, Zhang W, Doherty M. Are joints affected by gout also affected by osteoarthritis? Ann Rheum Dis 2007;66:1374-7.

6. Forbess LJ, Fields TR. The broad spectrum of urate crystal deposition: Unusual presentations of gouty tophi. Semin Arthritis Rheum 2012;42:146-54.

J Rheumatol 2013;40:8; doi:10.3899/jrheum.130152 